\title{
Form Follows Environmental Energy: Ecological Heat In Contemporary Vernacular Architecture
}

\author{
Meiting $\mathrm{HE}^{1}$ and Linxue $\mathrm{LI}^{2}$ \\ ${ }^{1} \mathrm{PhD}$. Candidate, College of Architecture and Urban Planning, Tongji University, China \\ ${ }^{2}$ Professor, College of Architecture and Urban Planning, Tongji University, China
}

\begin{abstract}
The aesthetic of architecture changes with the history, and its evolution is a dynamic, humane and regional process. The contemporary China is in the double transition periods of traditional and modern, modern and postmodern, therefore the value of architecture lost its order caused by the overlapping and conflicting of different values in different periods, either external "image" or intrinsic "meaning", are in a state of disorder. With the advent of modernization, traditional architecture seems to be gradually forgotten and abandoned. However, many traditional villages still circulate the environmental wisdom that contemporary architects still use in their designs. Most of the traditional houses all over the world use local building material, make full use of renewable energy, using the natural energy of natural climate actively such as light, heat, wind to adapt to the climate environment, with good adaptability to the local climate, topography and, is a model of passive building technology. This article attempts from Three angles to explore, which are the diagram and theory, simulation software, and environment measurement of Chinese traditional village. Through the above research, we try to find the coupling between traditional local-style dwelling houses and modern residence in the design.
\end{abstract}

\section{Introduction}

Since the 20th century, with the advancement of technology and science brought about by the second industrial revolution, people's concept of architecture has also undergone tremendous changes. At the same time, the drawbacks under the modernization process have gradually emerged, and the ecological environment has become one of the most prominent contradictions. The exhibition, The Seed of Time, which opened at the Himalaya Art Museum in Shanghai in 2017, calls for immediate action to improve the climate. The exhibition attempts to integrate art, literature (science fiction), science and technology, sociology, environmental science, biology. Learning, medicine, etc., to better understand the current pressing environmental and social issues, and to explore a sustainable solution. In the context of increasingly serious environmental and ecological problems, Shanghai Seeds discusses modernity and sustainable development from an interdisciplinary perspective, with the intention of discussing, reflecting and responding to what kind of world the upcoming 22nd century will usher in. action. In the exhibition, Broun Latour discussed the relationship between local and scholars and the intellectual community by discussing the topic of "resetting modernity", at the moment, how to reexamine the concept of "modernity".

However, due to the semantic confusion between "modernity" and "modernization", the latter can usually be understood as a simple, linear process of social development, which easily leads to blind worship of "modernization" of architecture and a simple understanding of "rationality" of science. Essentially, it is a one-dimensional development of architecture that catches up with fashion and loses self, which leads to the neglect of the connotation of "aesthetics" of architectural modernity. Therefore, in the post-modern context, this paper ponders whether architectural aesthetics still exists, and what is the form and significance of its existence? The study of architectural aesthetics in China is easily influenced by social and political trends, and its study cannot be confined to the practical category of "form to form". Therefore, this paper introduces the topic of modernity and contemporary, with contemporary Chinese vernacular architecture as the object of study, trying to excavate the trace of its ecological aesthetics and environmental development.

\section{Environmental diagram and ecological aesthetics}

With the advancement of human science and technology, the relationship between man and nature, the transformation of architectural aesthetic value can be roughly divided into the following four, the natural aesthetics of primitive society, succumb to nature; the classical aesthetics of early civilized society, trying to count and rational Conquering nature; functional aesthetics in the modern industrial era, with technological

Corresponding author: hmt@tongji.edu.cn 
revolution over everything; the ecological aesthetics of postmodern society emphasizes the integration of man and nature. Therefore, the following paper focuses on the ecological aesthetics of post-modern architecture, form follows energy, since the development of modern architecture.

\subsection{The revival of lofty aesthetics and the transformation of architectural aesthetics}

The definition of sublimity shapes the modern aesthetic discourse system and is synchronized with postmodernism. The theorists of contemporary studies of sublime aesthetics attempt to reinterpret the historical traditions that began in the first century $\mathrm{AD}$ and developed during the Enlightenment. The comments of Edmund Burke and Kant were published at the beginning of modernity and became the most important theoretical source of the 18th century. The sublime reflection can be used to reposition the discourse of the architectural discipline, transcending formalism. [1]

In the field of architecture in the 20th century, the sublime or the beautiful was deliberately suppressed by theorists and designers, and they were eager to distinguish them from the past. In order to achieve the "fundamental break" pursued by modernism and the history of the discipline, the terminology of aesthetic theory must be changed. Some modernist arguments call for an aesthetic "white paper state" or the use of scientific principles for design, replacing the previous retouching and artificial. The positivist values rationality and function, and rejects sublimity and beauty as subjective architectural elements. Postmodernism's restoration of sublime aesthetics (and its restoration to the United States) has enabled the extension and development of the theory. The beauty of architecture, in the narrow sense, refers to the beauty of a single building, and in a broad sense is the architectural aesthetics that spans the unit and encompasses the group. As early as the end of the 19th century, the architect Louis Sullivan pointed out that since function is regarded as necessary for life, the relationship between architectural form and its function should naturally be recognized as necessary for aesthetics. To this end, he proposed the slogan of Form follows function, that is to say, the external beauty of the building should obey the needs of the internal functions of the building. The architectural form should be formed by internal functions naturally, instead of applying the ready-made historical style, or Feel free to do whatever you want. Later, on the basis of the functional aesthetics of Sullivan, Wright further proposed the architectural aesthetics of Organic Architecture from the criteria of biological evolution, and advocated that architecture is a natural embellishment. By the end of the 1920s, the house is the living machine proposed by Le Corbusier further pushed the architectural aesthetics of functionalism to a climax. It was also an emphasis on the proportion and harmony of architecture, and the scrutiny of geometry and numbers. The aesthetics of modernist architecture is a revival of the geometric aesthetics of some classical rationalism.

\subsection{Natural, technical and social environment based on energy perspective}

Building energy conservation is an important way to reduce energy shortage and realize low carbonization development. [2] Energy is the ability of a physical system to work for other physical systems.[3] It is the essential attribute of material, such as heat energy, mechanical energy and many other forms. In buildings, energy is mainly reflected in the form of heat. Modern native buildings are often criticized for lack of response to the local environment [4]. In many traditional buildings, both primitive and vernacular, you can see some architectural problems that use clever solutions to deal with extreme weather and maintain a comfortable indoor climate [5]. The natural materials used in traditional native buildings are generally conducive to creating a sustainable and healthy built environment [6-7]. Many comparative studies of traditional and modern native architecture have revealed the inner logic of some excellent traditional native architecture. From the historical perspective, it can be proved that the traditional dwellings through the transformation or reconstruction of the villagers should be able to maintain a comfortable environment for a longer period of time than the modern villagers build their own houses [8]. Therefore, both villagers and designers who are transforming and building vernacular buildings must adopt some effective methods to solve this problem and provide appropriate solutions for the future environment of contemporary rural architecture.
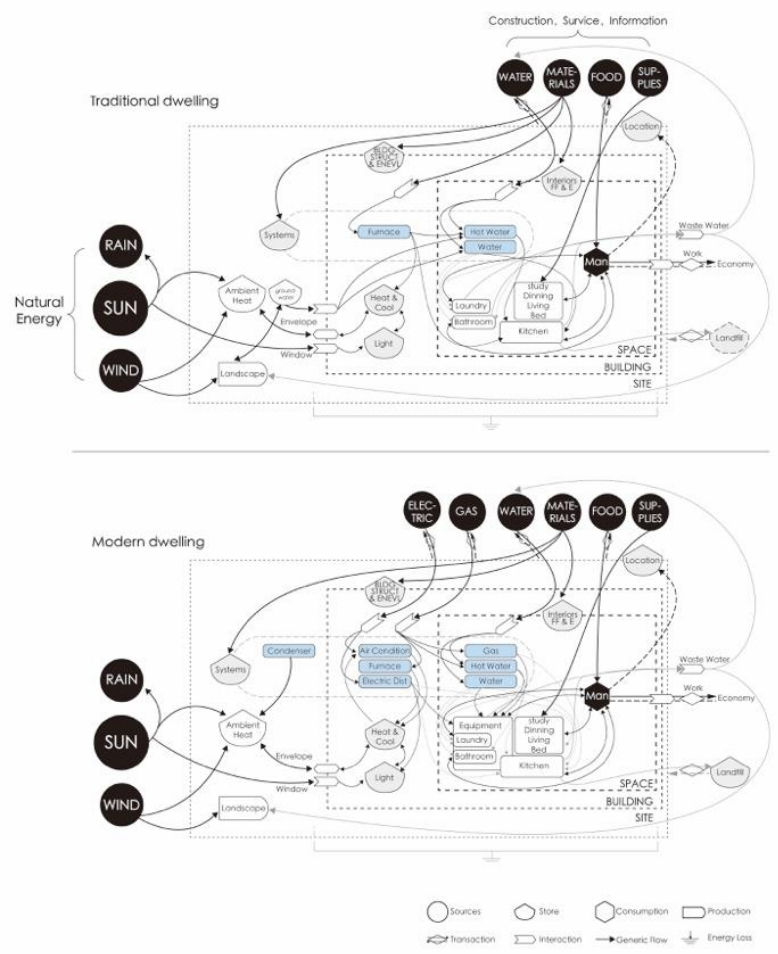

Fig. 1. Traditional and Modern Dwellings' Energy Flow Diagram

According to the transformation of Odums'( Odum 2002) energy diagram, the author redraws the energy diagram of residential buildings. The input of climate energy, materials and construction, and other energy sources is 
the main source of external energy for the building environment. Traditional dwellings can maximize the use of climate energy to make buildings interact with them. In terms of local building materials and construction, they are usually built with local materials, relatively low technology means. At the same time, the energy sources also reduce the input of fossil energy. The climate adaptability design of contemporary vernacular architecture can achieve the effective combination of selfsufficient energy supply and architectural form, and correctly match the purpose and object of energy utilization. However, the traditional and contemporary local residences obviously have different kinds of building energy vocabularies. In the natural environment (site), technical environment (asylum interface), social environment (residence scene), the various kinds of flow of energy are not the same. In the context of Chinese vernacular architecture, drawing the energy diagram of vernacular dwellings helps to build up the possibility of maximizing cost and maximizing performance in the pursuit of material wealth and exploring uncertain factors of design.(Figure 1)

\subsection{Influence factors}

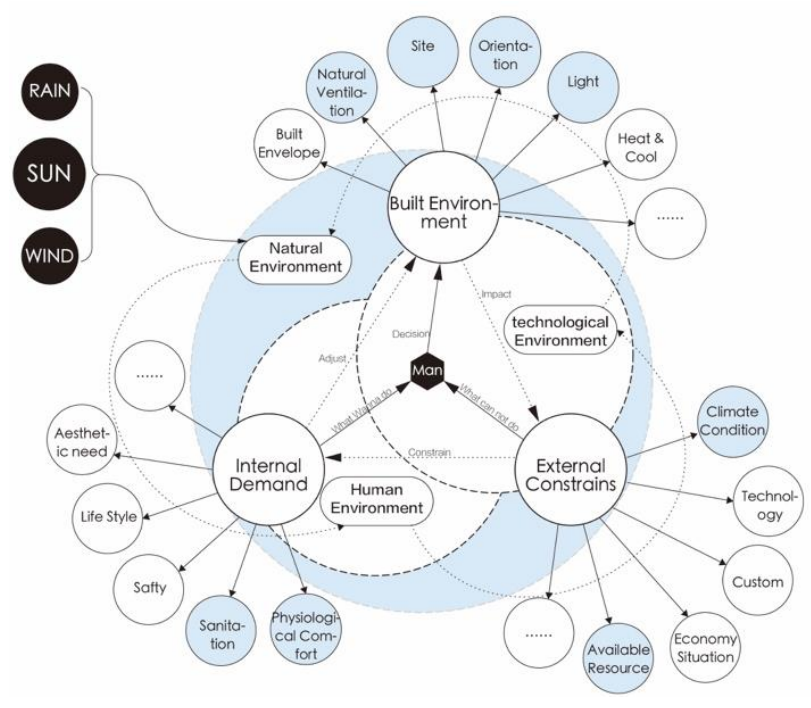

Fig. 2. Diagram of Three different environments

The construction process of the residence reflects the complex interaction of multi dimensions and multi elements.[9] Especially in the construction of vernacular dwellings in China, besides considering the climate factors, we need to consider the elements such as economy, life habits and family composition. Therefore, the construction of a residential house cannot be determined solely by a certain element. The factors that influence the construction of vernacular dwellings include not only the objective elements such as climatic conditions, geographical conditions, technology, materials, but also the social and cultural elements such as economy and belief, including personal needs in traditional Chinese thoughts. In residence form and culture, Amos Rapoport elaborated on the influencing factors of the choice of residential morphology: "under the established climate conditions, building materials and technology conditions, the definition of ideal life for a particular community is defined. The process of all this pursuit is influenced by the social and cultural factors (social-cultural factors)." In the material and objective factors, Rapport discussed in detail how climate affects the architectural form of residential buildings, and put forward the concept of "climate scale". As for climate scale, human beings are often unable to control outdoor climatic conditions, but the purpose of housing construction is to cope with the impact of unsustainable climate stress on users. At the energy point of view, the more severe the climatic factors are, the lower the control force of the building form, the more obvious limitation of the natural energy. On the contrary, the better the climate, the more freedom of human control of the architectural form, and the limitation of natural energy is not obvious or even negligible. At this time, other factors will become the main force of the architectural form.

Therefore, under the influence of specific material conditions and social and cultural conditions, the folk house is not only the satisfaction of people to the internal needs, but also the material embodiment of the life form of the vernacular architecture. The design and construction of local buildings have the unified characteristics of the decision-makers, the builders and the users. Its choice of architectural form is often based on previous experience of residence, and the achievement after completion will become the experience and feedback to the next decision. In the feedback mode of local building construction, the control of all kinds of influence factors cannot be separated. Among them, people play the role of both users and decision-makers, and have three links with architectural forms through demand, function and evaluation. (Fig.2)

\section{A case study: climate adaptability of Zhejiang traditional and modern dwellings}

\subsection{The architectural features of traditional and modern dwellings}

Most of the traditional houses all over the world use local building material, make full use of renewable energy, using the natural energy of natural climate actively such as light, heat, wind to adapt to the climate environment, with good adaptability to the local climate, topography and, is a model of passive building technology[10].

The traditional dwellings in Yiwu, Zhejiang, are affected by the terrain. On the site and layout of the building, the buildings have taken full account of the characteristics of the local hills, most of which are built on the back of the mountain surface water. The earliest settlements were only near the river and small streams. As the natural environment changed from adaptation to transformation, they gradually spread to the rivers and sea. The gates of the local dwellings are mainly toward the south. The architectural forms are the quadrangle and tree-courtyards, and the blocks of the buildings are more regular. The buildings are combined to form a single, juxtaposed or multiple compound building group to make the overall layout of the building better meet the needs of the use. 
However, the floors number of modern dwellings in Yiwu are generally more than the traditional, all of which are $2-5 \mathrm{~F}$, and brick wall structure is the main structure. Most of the dwellings are built in the homestead, with a strong feature of local climate suitable technology. Other features are similar to ordinary modern dwellings.

In air temperature and humidity measurement, considering the difference of outdoor microclimate at different heights, two different dwellings were measured nearby. 3 measuring points were set up in the modern dwelling, and 7 measuring points were set up in the traditional dwelling. During the test, the temperature and humidity and the wind speed were continuously monitored, and the data collection interval was 1 hours. The height of the indoor test points is between $1.2-1.5 \mathrm{~m}$. And in order to avoid the impact of indoor heat sources on the test results, the two buildings were measured without the air conditioning and other indoor heat sources.
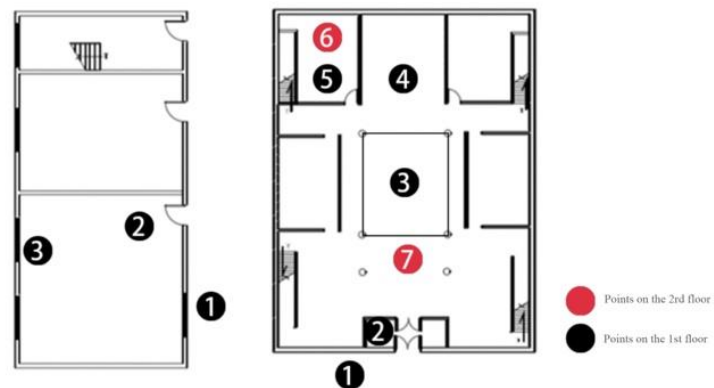

Fig. 3. Measurement points in modern dwelling and traditional dwelling

The 3 measurement points of modern dwelling are as follows: the test point 1 in the residential outdoor, the test point 2 in the house room, and the point 3 in the indoor window of the residence. 7 measuring point of traditional dwelling were: 1 measuring points outside, the measuring point 2 in the hallway, measuring point 3 in the courtyard, the measuring point 4 in living room, and measuring point 5 and 6 for the one or two floor indoor, measuring point 7 on the two floor corridor. The distribution of the measured points of the two buildings is shown in Figure 3, and the red point represents the second floor position.

\subsection{The Settlement Space of Traditional and Modern Dwellings}

By measuring the climate data of traditional dwellings and modern dwellings in Yiwu Shentan village, we can get the characteristics of local vernacular architecture in settlement, building space and material construction. From the analysis of thermal comfort strategy in Yiwu area, we know that the effectiveness of improving thermal comfort level is the highest in winter, so the climate measurement in winter is of great practical significance.

\subsubsection{Solar Radiation}

The buildings have the best local sunshine in the direction toward south, they can get more heat radiation in the winter. The summer wind blowing can remove heat from the gable, at the same time the courtyard can also form hot air indoor and take the heat away. By simulating the annual average sunshine time of the settlements, we get the result of figure 4 . The sunshine duration between most buildings is only about one hour, the larger aspect ratio and the direction of the building get better sunshade effect.

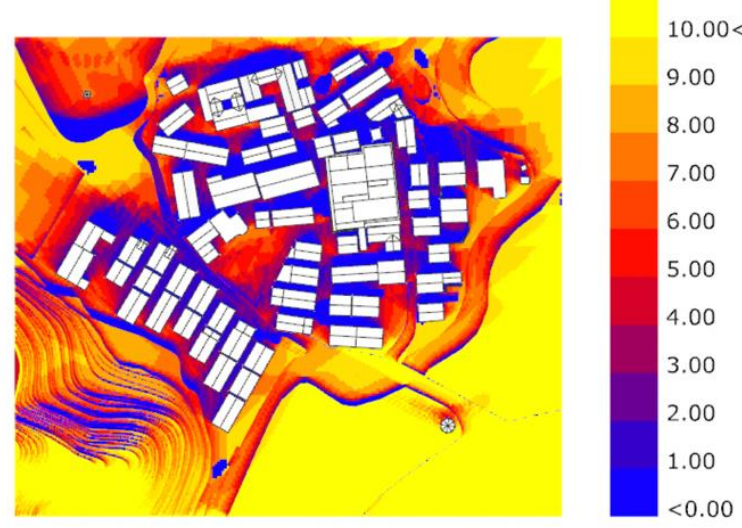

Fig. 4. The analysis of the sunshine time of the settlement

\subsubsection{Wind Environment}

The black lines in the wind speed change map (Figure 5) are the outdoor wind speed, the dotted lines are the wind speeds of the second floor, and the rest are the distribution of the wind speeds in the first floor. Because the wind environment measurement time is one hour, but the wind change situations are more complex. The broken lines in change chart only act as data connection. There is no real wind speed significance. The measured data are at the dots. The figure can be found in velocity sorting from large to small: main hall, hallway, the second floor corridor, the second floor indoor, the first floor indoor and the patio. The wind speed at the courtyard is close to the outdoor wind speed, and the wind speed at other points are relatively high. In winter, good natural ventilation can ensure air quality through air flow.

Based on the common east direction and $2 \mathrm{~m} / \mathrm{s}$ as the initial speed, the whole village's wind environment is simulated by software Pheonics. At different heights, the whole village's wind environment is good. As shown in Figure 6 , there is no obvious wind shadow zone, the wind speed in the settlements at between $2-4 \mathrm{~m} / \mathrm{s}$. At the pond at the centre of the village, the wind speed is low, and the wind speed is high between the streets and the streets. The wind can easily cross the street from the East and form the flow of wind throughout the settlement. In summer, wind can take out indoor heat through streets and courtyards, and because winter buildings are more closed, and wind environment has little influence on indoor insulation.

\subsubsection{Temperature and Precipitation.}

The temperature of this measure refers to the temperature of the dry ball(Figure 7). The outdoor temperature is between $-0.50-10.5{ }^{\circ} \mathrm{C}$ and the temperature at the courtyard is more intense than the 
outdoor temperature, at $-0.23-7.94{ }^{\circ} \mathrm{C}$, and at noon, the temperature is higher than the outdoor temperature, and the other time is about $1-2^{\circ} \mathrm{C}$ lower than the outdoor temperature; The indoor temperature in indoor temperature is at $0.26-6.27^{\circ} \mathrm{C}$, and the temperature is intense in the morning, and the temperature in the afternoon is constant; The second floor indoor temperature at $0.12-5.80^{\circ} \mathrm{C}$ is also intense in the morning, and relatively constant in the afternoon. The temperature of the hallway changes significantly, because the courtyard at noon will accept the light and heat.

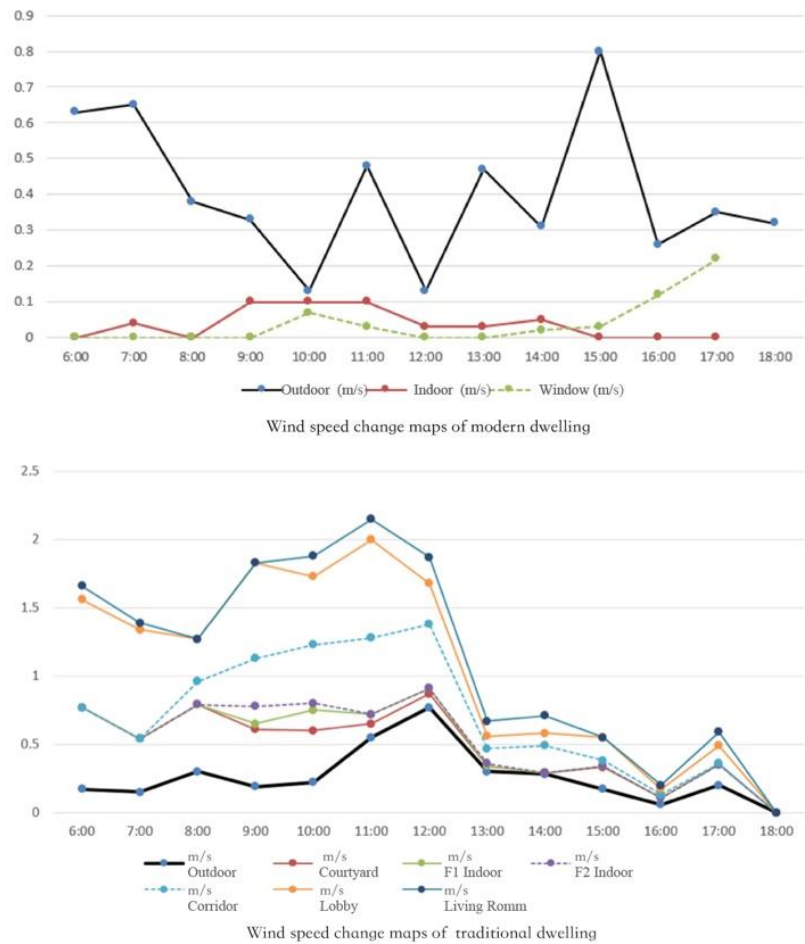

Fig. 5. Wind speed change maps of modern dwelling(Top) and Traditional dwelling(Bottom
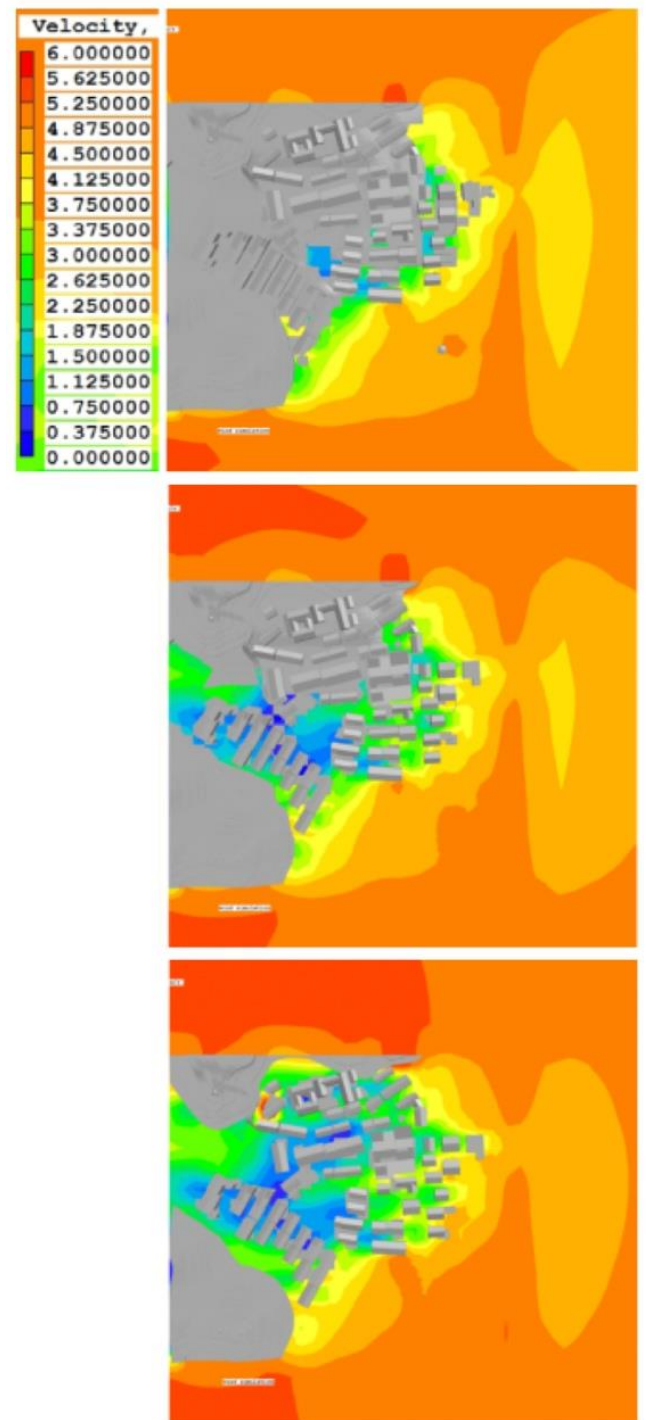

Fig. 6. Wind simulation result at different levels of height

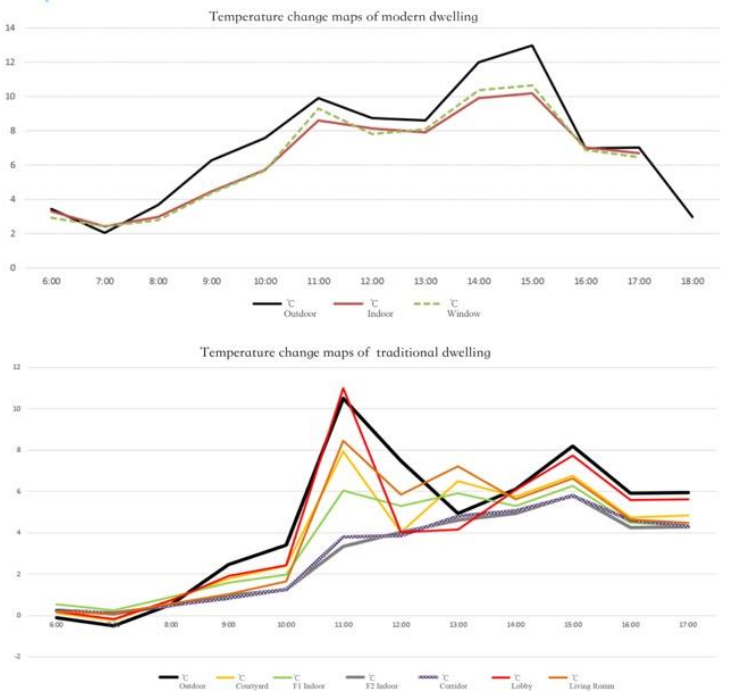

Fig. 7. Temperature changes of traditional dwellings and modern dwellings 


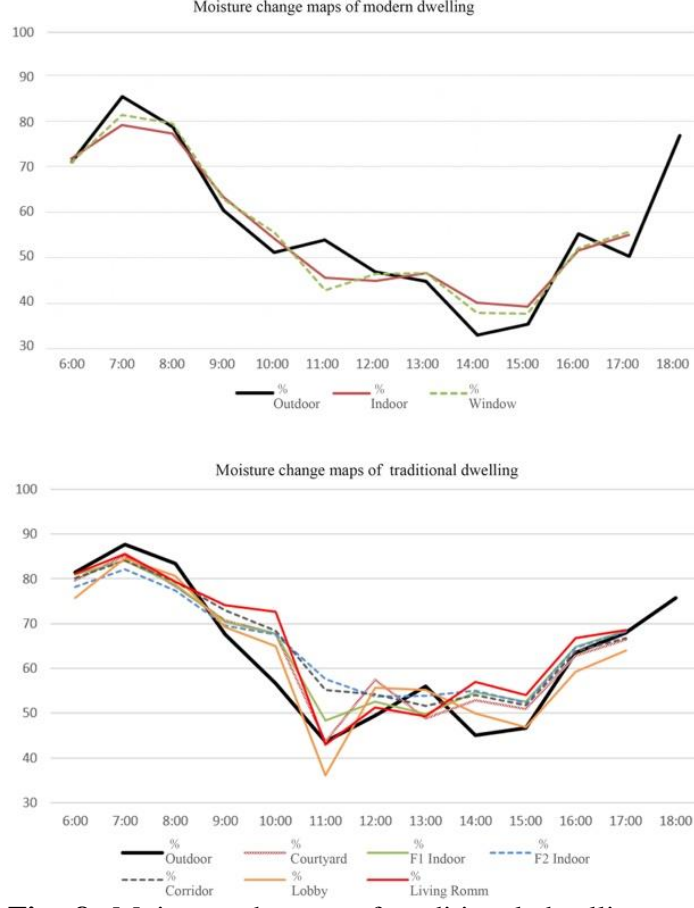

Fig. 8. Moisture changes of traditional dwelling and modern dwelling

We can find that with the change of temperature, the change of humidity is the opposite(Figure 8). At 11:00, humidity decreased obviously, and humidity change of the hall and courtyard is at the most intense. The change of humidity in the first floor is more obvious than that of the second floor, and the change of humidity in 12:00 15:00 is smaller and the rest of time changes greatly.

\section{Conclusion}

Since postmodern, architects have tried to touch this topic. Subsequently, a group of post-modern ecoarchitects emerged, who also focused on the ecology and vernacular architecture. They called on architectural forms to follow the dynamic changes of energy. They believed that the focus on energy and resources should not be a constraint on form, nor a technical standard unrelated to the theoretical design methodology, but a turning point in architectural design methods.

Ecological aesthetics is an organic combination of ecology and aesthetics. It is not a simple patchwork of two disciplines, but the study of architectural aesthetics using ecological theories and methods. Modern architects should try to absorb the ecological point of view into architectural aesthetics, thus systematically constructing an architectural design methodology of human and natural aesthetic concepts and ecological concepts.

Through the analysis of the indoor and outdoor temperature, humidity and wind environment, the transition space such as the patio and corridor can effectively improve the climate adaptability. These important places of life provide people better than the outdoor environment, and also play a climatic buffer to indoor space. In the former residence, the use of courtyard houses and thicker brick and high heat storage materials make the space temperature slow, but the thermostat characteristics of high heat storage make it maintain thermal stability for a long time. However, the temperature and humidity of modern dwellings are obviously changed with the outdoor, and the heat is rapidly rising after the solar radiation, but it is also faster in the evening because of the poor thermal storage of the materials. At the same time, under the condition of maintaining the need of temperature, a relatively closed enclosure structure has been formed, and the air circulation is weak.

After analysing the measured and simulated data from the perspective of climate adaptability, it is found that in winter, the stone roof of former residence can receive more heat radiation, and its high heat storage makes the space thermostat stronger. Near noon time, the courtyard space could receive direct sunlight, which makes a relatively large effect on the nave and a layer of floor to improve indoor temperature. At the same time, the courtyard space also has a good effect on the indoor air circulation and the air quality regulation. The double window of the residence can promote convection ventilation in summer, also can achieve better insulation in winter.

In fact, for all ecological buildings, technology is undoubtedly only a tool. Only by incorporating the technical rationality of modern architecture into the aesthetic value, the technology of architecture can move towards the balance of maintaining the ecological and the sustainable development of human society and the poetic return of life. The architectural ecological aesthetics emphasizes the poetic expression of technology. The technique of integrating sensuous art has provided a direction of ecological significance and characteristics of the times for the diversified development of architecture. The ecological practice of vernacular architecture based on this logical clue should be the mainstream of the 21 st century, but it is not important whether the form itself is novel or not.

The development of contemporary architecture provides space and atmosphere for post-modern architectural aesthetics, especially the ecological concept. Combined with the transformation of traditional ideas and lifestyles, the aesthetics of architecture is constantly adjusted and integrated. This makes today's architectural design present a modern and post-modern, Eastern and Western collateral and intricate situation. 


\section{References}

1. K. Nesbitt, Theorizing a New Agenda for Architecture: An Anthology of Architectural Theory 1965-1995 (Princeton Architectural Press, 1996)

2. A. M. Omer, Energy, environment and sustainable development, Renewable and sustainable energy reviews, 12, 9 (2008)

3. G. Hausladen, Climate design: solutions for buildings that can do more with less technology (Birkhauser, 2005)

4. S. R. Sangkertadi, A. Tungka, Thermal Comfort Comparison of Traditional Architecture and Modern Style Housing in North Sulawesi Indonesia, Proceeding of 9th SENVAR+ 2nd ISESEE, Selangor, Malaysia, 1-3 (2008).

5. Z. Y1lmaz, Studies on energy efficient design in ITU sustainable energy research group, In Energy conservation and insulation congress and exhibition for sustainable environment, Istanbul (2004)
6. R. Ooka, Field study on sustainable indoor climate design of a Japanese traditional folk house in cold climate area, Building and Environment, 37(3), 319329. (2002)

7. L. Borong, T. Gang, W. Peng, S. Ling, Z. Yingxin, Z. Guangkui, Study on the thermal performance of the Chinese traditional vernacular dwellings in summer, Energy and Buildings, 36(1), 73-79(2004)

8. E. Arens, M. A. Humphreys, R. de Dear, H. Zhang, Are 'class A'temperature requirements realistic or desirable, Building and Environment, 45(1), 4-10, (2010)

9. S. Gou, Z. Li, Q. Zhao, V. M. Nik \& J. L. Scartezzini, Climate responsive strategies of traditional dwellings located in an ancient village in hot summer and cold winter region of China, Building and Environment, 86 (2015)

10. Z. J. Zhai, J. M. Previtali, Ancient vernacular architecture: characteristics categorization and energy performance evaluation. Energy and Buildings, 42, 3 (2010). 